\title{
A Descriptive Study of the Knowledge-Base of Malaria between the Visually-impaired and the Non-Visually impaired in Two Primary Schools in Lagos, Nigeria; implications for health education

\section{Abstract}

Background: The study was carried out in two primary schools in Lagos State, Nigeria. One hundred students were from Pacelli School for the Blind and one hundred and sixty-four students were from Onitolo Primary School, a main stream school. The study compared the knowledge base of the two groups on malaria prevention and treatment options. Approval for the study was granted by the Ethics Committee of the Lagos University Teaching Hospital, Nigeria and consent was sought from parents/guardians of the students and from the principals of the two schools.

Method: The instrument of data collection was a close ended questionnaire. The average time it took to fill the questionnaire was twenty minutes. Analysis of categorical variables was done by Chi-Square Analysis.

Results: The respondents from Pacelli School for the Blind were older than the respondents from Onitolo Primary School when matched by class in primary school $(P<0.05)$. The majority of the respondents were Yorubas, 178 (70.5\%). In Pacelli School, the number of males that were visually-impaired was more than the number of females $(P<0.05)$.

There was a statistically significant difference on their knowledge base on the cause of malaria $(P<0.05)$. The students from Pacelli School $92(92 \%)$ knew that malaria was caused by mosquitoes and only $75(45.7 \%)$ of the respondents from Onitolo knew that malaria was caused by mosquitoes. The age at which respondents from Pacelli School became visually impaired was not statistically related to the correct knowledge that malaria was caused by mosquito $(P<0.05)$.
Titilola T. Obilade MBBS, Ph.D.

\section{Contact information:}

Titilola T. Obilade MBBS, MPH,

FMCPH, MWACP, MILD, Ph.D.

Senior Education Specialist Learning Sciences and Technology 144J Smyth Hall.

Virginia Polytechnic Institute and State University.

Blacksburg, Virginia, 24061-0488.

”obilade@vt.edu 
The number of respondents that preferred the parenteral route for treatment of malaria was fewer in Pacelli School than in Onitolo School $(P<0.05)$. A greater number of respondents from Pacelli School did not like to take malaria tablets because the malaria tablets were bitter $(P<0.05)$. The major source of information about malaria from both schools was from their doctors and other health personnel 116 (43.9\%). When the responses from both groups were combined, the least source of information about malaria in both groups was from teacher/school 27 (10.2\%).

Two hundred and twenty-seven (85\%) of the respondents would choose a doctor as their health-care provider if they had malaria $(P>$ 0.05). In Pacelli School, 44 (44\%) of the respondents had had malaria in the past twelve months. In Onitolo School, 49 (29.9\%) of the respondents had had malaria in the past twelve months. There was no statistically significant difference in the number of times both groups had had malaria in the past twelve months.

Conclusion: There were more visually-impaired males in Pacelli School than females. There was a statistically significant difference on their knowledge base on the cause of malaria. More students from Pacelli School had the correct knowledge on the cause of malaria. The major source of information about malaria from both schools was from their doctors and other health personnel. Teacher/School was the least source of information about malaria when responses from both schools were combined. Health Education on preventable diseases like malaria should be strengthened in both schools. More schools for the visually-impaired should be replicated across the states in Nigeria and more schools for the visually-impaired should be replicated in Lagos State.

Keywords: Malaria; Health Education; Visually-impaired; knowledge base; Pacelli School; Onitolo School; The Blind; Treatment; Prevention; Lagos, Nigeria. 


\section{Introduction}

Objectives:

1. To determine the socio-demographic pattern of pupils in the school for the visually-impaired and in the main stream school.

2. To determine the knowledge-base on the cause and treatment options for malaria in the visually-impaired group.

3. To determine the knowledge-base on the cause and treatment options for malaria in the non-visually impaired group.

In 2012, ninety percent of deaths due to malaria occurred in Africa [1]. In 2012, there were over 300,000 deaths from malaria [2]. Two thirds of the people that suffer from malaria are from West Africa. A prompt diagnosis and an early treatment continue to be the mainstay of the current approach to malaria control. The World Bank estimates that the Gross Domestic Product of some African countries is reduced by $1.3 \%$ due to malaria [3].

In a recent study conducted in the south eastern part of Nigeria to determine the economic burden of malaria, the findings showed that even though the government was providing free malaria treatment to mothers and children in public health facilities, the indirect costs of care and lost pay outweighed the direct costs of treatment of malaria [4]. A separate study conducted in Uganda to determine the economic loss due to malaria showed that the economic burden of malaria reduced the Gross Domestic Product of Ugandans [5].

The correct knowledge on the cause, control and treatment of malaria will reduce the deaths and morbidity due to malaria. Health Education is a level of prevention and is usually cheaper than a curative approach. In order for the preventive approach to be achieved, the knowledge-base of the two study groups must be elicited. The two groups were chosen from the primary school because a primary school is a place of secondary socialization. In addition, health education is part of a school health program and the study would determine their source of knowledge on malaria. The study helps to identify any deficit if any in the knowledge base of malaria. When a pupil has the correct knowledge on the cause, treatment and cause of malaria, morbidity and mortality will be reduced because s/he would practice a healthy life style. Health education and assessment of handicapped children is a component of a school health service.

Health education program introduced in a school in Kenya improved the health status of the children [6]. A separate study conducted in Central Zambia concluded that health education could improve the health of the school children studied [7]. Many of the school children studied in Central Zambia had hookworm, schistosomiasis and malaria. However, among the three infections identified, the highest incidence was found in malaria [7]. In a school health program in Tanzania, annual malariometric surveys on children showed that plasmodium falciparum accounted for one hundred percent of the infections. Further, the researchers were able to teach the teachers in the school to diagnose and treat malaria in the school children [8]. The study concluded that teachers could play a major role in school health programs if they were supported by health and educational authorities [8]. Another study conducted in the south eastern part of Nigeria showed that as the number of years of formal education increased, the belief that herbal remedies could treat malaria decreased [9].

\section{Materials and Methods}

\section{Pacelli School for the blind and partially sighted children}

Pacelli School for the Blind and partially sighted children was named after Pope Pius XII who was Eugenio Pacelli. The first set of pupils arrived on the $1^{\text {st }}$ of June, 1961. They were two boys and two girls. There was only one building for the pupils, the office block and the convent for the sisters 
managing the school. In June 1962, Pacelli School for the Blind was officially opened. It was built by the Federal Government of Nigeria as a voluntary agency school. It was granted aide by the Federal Ministry of education until 1967 when the Lagos State Government assumed responsibility. It was handed back to the Catholic Mission on the $5^{\text {th }}$ of August 1997. It has boarding facilities. The curriculum is designed to prepare pupils for entry into Secondary Schools. The Pacelli School is entirely funded by charity. It has the capacity to accommodate 100 students. The subjects taught include Religion, English, Mathematics, Science, Creative Arts, Health Education, Social Studies, Home Economics, Music, Physical Education, Mobility Training, Typewriting, Swimming, Braille Reading and Writing. Many of the graduates of the school are married and some have become teachers in the schools.

\section{Onitolo Primary School}

Onitolo Primary School was formerly known as Government Demonstration School and was initially established as a Government Teacher Training College. After the creation of Lagos State in 1967, the administration and financing of both the teachers' college and the school was transferred to the State Education Ministry. The population of the school rose to over 2000 in 1976. Onitolo Primary School has always been a day school. The pupils do not pay fees apart from the Parents Teachers Association fees which is an equivalent of ten dollars.

\section{Type of Study}

This was a descriptive, cross-sectional study. Pupils from Pacelli school for the Blind and PartiallySighted, Surulere, Lagos, Nigeria and pupils from a main stream public school, Onitolo Primary School also in Surulere, Lagos were selected as participants in the study. Ethical clearance for the study was given by the Research and Ethics Committee of the Lagos University Teaching Hospital. Consent was also obtained from the parents/guardians of the pupils. In addition, consent was obtained from the principals of the two schools.

\section{Data Collection}

Onitolo Primary School was selected from a comprehensive list of 61 Public main stream primary schools in Surulere Local government area of Lagos State. The school was selected by simple random sampling. Unanswered questions were considered as non-responses.

Inclusion Criteria for the visually-impaired from Pacelli School

1. Any pupil that was visually-impaired and was aged between 6 and 24 years old by their last birthday.

\section{Exclusion Criteria for the visually-impaired from Pacelli School}

1. Any pupil that was not between 6 and 24 years old as at their last birthday.

2. Any pupil that had other disabilities affecting any of the other senses.

Inclusion Criteria for the non- visually-impaired from Onitolo Primary School

1. Any pupil that was between 6-24 years as at the last birthday.

Exclusion Criteria for the non- visually-impaired from Onitolo Primary School

1. Any pupil that was not between 6-24 years as at the last birthday.

\section{Ethical Issues}

In each of the two schools, the study took two weeks and the students' timetable was slightly disrupted for the period of study.

\section{Instrument of Data Collection}

\section{Questionnaire}

The questionnaire consisted of a total of 22 questions. The questionnaire was divided into five parts consisting of questions covering socio-demographic data, knowledge questions on the cause of malaria, knowledge questions on prevention of malaria, 


\section{INTERNATIONAL ARCHIVES OF MEDICINE \\ Section: Applied Technology in Medicine

questions on school absenteeism due to malaria and questions on the route for the treatment of malaria. The Principal Investigator trained the teachers for the non-visually impaired pupils on how to ask the question. The pupils from the school for the visually-impaired were interviewed by their teachers who interviewed them verbally using the structured questionnaire. The Principal Investigator was not allowed to interview the pupils from the school for the visually-impaired.

In Onitolo Primary School, the Principal Investigator interviewed some of the pupils verbally by explaining and reading each question to the respondents in each class.

\section{Data Analysis and Interpretation}

Data was collected and analyzed for statistical association. Raw data were coded and input into the computer. Errors in the data entry were cleared to remove entry errors. Tests of association analysis and interpretation were conducted by the Principal Investigator and reviewed by a biostatistician. Analysis was done only on the responses. The results were presented as tables. Statistical association using Chi-Square was used to test for association between categorical variables.

\section{Results}

The main results are included in the following tables:

Table 1: Socio Demographic Distribution of Respondents.

\begin{tabular}{|c|c|c|c|c|}
\hline \multicolumn{5}{|c|}{ Number of respondents in each school } \\
\hline School & & \multicolumn{2}{|c|}{ Frequency } & Percentage \\
\hline Pacelli & & \multicolumn{2}{|c|}{100} & 37.9 \\
\hline Onitolo & & \multicolumn{2}{|l|}{164} & 62.1 \\
\hline Total & & \multicolumn{2}{|l|}{264} & 100 \\
\hline \multicolumn{5}{|c|}{ Sex of respondents in both schools } \\
\hline Sex & Pacelli n (\%) & Onitolo n (\%) & Total n (\%) & P Value $<0.05$ \\
\hline Female & $41(41.0)$ & $92(56.1)$ & $133(50.4)$ & \\
\hline Male & $59(59.0)$ & $72(43.9)$ & $131(49.6)$ & \\
\hline Total & 100 & 164 & 264 & \\
\hline \multicolumn{5}{|c|}{ Religion of respondents in both schools } \\
\hline Religion & Pacelli n (\%) & Onitolo n (\%) & Total n (\%) & $P$ Value $<0.05$ \\
\hline Christian & $78(78)$ & $92(56.1)$ & $170(64.4)$ & \\
\hline Muslim & $22(22)$ & $72(43.9)$ & $94(35.6)$ & \\
\hline Total & 100 & 164 & 264 & \\
\hline \multicolumn{5}{|c|}{ Ethnic distribution of respondents in both schools } \\
\hline Ethnic Group & Pacelli n (\%) & Onitolo n (\%) & Total n (\%) & P Value $<0.05$ \\
\hline Yoruba & $62(62)$ & $124(75.6)$ & $186(70.5)$ & \\
\hline Hausa & $1(1)$ & $6(3.7)$ & $7(2.7)$ & \\
\hline Igbo & $19(19)$ & $17(10.4)$ & $36(13.6)$ & \\
\hline Others & $18(18)$ & $17(10.4)$ & $35(13.3)$ & \\
\hline Total & 100 & 164 & 264 & \\
\hline \multicolumn{5}{|c|}{ Age distribution of respondents in both schools } \\
\hline Age (in Years) & Pacelli n (\%) & Onitolo n (\%) & Total n (\%) & $\begin{array}{c}\text { Non Response }=3 \\
\text { P Value } \\
<0.05\end{array}$ \\
\hline $6-10$ & 33 (33.6) & 109 (66.9) & $142(54.4)$ & \\
\hline $11-15$ & $46(46.9)$ & $53(32.5)$ & $99(37.9)$ & \\
\hline $16-20$ & $17(17.0)$ & $1(0.01)$ & $18(6.9)$ & \\
\hline $21-25$ & $2(2)$ & $0(0)$ & $2(0.8)$ & \\
\hline Total & 98 & 163 & 261 & \\
\hline
\end{tabular}


Distribution of respondents in both schools according to fathers' occupation

\begin{tabular}{l|c|c|c|}
\hline Occupations & Pacelli $n(\%)$ & Onitolo $n(\%)$ & Total \\
\hline Doctors, Scientists & $10(10)$ & $23(14)$ & 33 \\
\hline Small business owners, teachers & $42(42.0)$ & $66(40.2)$ & 108 \\
\hline *Clergy, Pastors & $3(3.0)$ & $1(0.6)$ & 4 \\
\hline *Factory workers, agricultural workers & $2(2.0)$ & 0 & 2 \\
\hline *Domestic servants, casual employees & $1(1.0)$ & 0 & 1 \\
\hline *Unemployed & $3(3.0)$ & 0 & 3 \\
\hline **Clerks, Foremen, Forewomen, Artisans & $39(39.0)$ & $72(43.9)$ & 2 \\
\hline * Deceased & 0 & $2(1.2)$ & 264 \\
\hline Total & 100 & 164 & 2 \\
\hline
\end{tabular}

Distribution of respondents in both schools according to mothers' occupation

\begin{tabular}{l|c|c|c|c|}
\hline Occupations & Pacelli $n(\%)$ & Onitolo $n(\%)$ & Total & 1 \\
\hline Doctors, Scientists & $1(1.0)$ & 0 & 88 \\
\hline Small business owners, teachers & $24(24)$ & $64(39.0)$ & 2 \\
\hline *Clergy, Pastors & $1(1.0)$ & $1(0.6)$ & 1 \\
\hline *Factory workers, agricultural workers & $1(1.0)$ & 0 & 0 \\
\hline *Domestic servants, casual employees & 0 & 0 & 10 \\
\hline *Unemployed & $3(3.0)$ & $7(4.3)$ & 162 \\
\hline **Clerks, Foremen, Forewomen, Artisans & $70(70.0)$ & $92(56.1)$ & 0 \\
\hline **Deceased & 0 & 0 & 264 \\
\hline Total & 100 & 164 & 2 \\
\hline
\end{tabular}

\begin{tabular}{|l|c|c|c|c|}
\hline & \multicolumn{1}{c}{ Distribution of respondents in both schools by class in primary school } \\
\hline Class in primary school & Pacelli $n(\%)$ & Onitolo $n(\%)$ & Total \\
\hline 1 and reception class & $42(42.0)$ & $5(3.0)$ & 47 \\
\hline 2 & $14(14)$ & $20(12.2)$ & 34 \\
\hline 3 & $11(11.0)$ & $32(19.5)$ & 43 \\
\hline 4 & $10(10.0)$ & $42(25.6)$ & 52 \\
\hline 5 & $12(12.0)$ & $34(20.7)$ & 46 \\
\hline 6 & $11(11.0)$ & $31(18.9)$ & 42 \\
\hline Total & 100 & 164 & 264 \\
\hline$*$ Categories in clergy, factory workers, domestic servants and unemployed were combined in Chi-Square calculation to \\
\hline
\end{tabular}


Table 2. Age at which respondents became blind in Pacelli School.

\begin{tabular}{|c|c|}
\hline Age in years & Frequency $n(\%)$ \\
\hline At Birth & $31(31)$ \\
\hline $1-5$ & $37(37)$ \\
\hline After the age of 5 & $32(32)$ \\
\hline Total & 100 \\
\hline
\end{tabular}

In this study, there was a total of 264 respondents. One hundred and sixty-four (62.1\%) of the respondents were from a public main stream school. In Pacelli School, there were more male respondents than female respondents but in Onitolo School, there were more female students $(P<0.05)$. Altogether, there were more female students in the total number of respondents 133 (50.4\%). About two-thirds, 170 (64.4\%) of the respondents were Christians. A greater proportion of the respondents were Yorubas 186 (70.5\%). In Pacelli School, majority of the respondents $46(46.9 \%)$ were aged between 11 and 15 years $(P<0.05)$. In Onitolo, majority of the respondents were aged between 6-10 years 109 (66.9\%). tolo, the greatest number of respondents were from primary four 42 (25.6\%). The oldest respondent in Pacelli was a female in the pre-primary one class. She was 23 years old and became blind after the age of five years. The ages at which students from Pacelli School became blind were almost evenly distributed.

Thirty-one (31\%) were blind at birth, 37 (37\%) were blind between the ages of 1 and 5 years old and 32 (32\%) were blind after the age of five years. Less than fifty percent of the respondents in both schools 105 (40\%) had not had an episode of malaria in the past twelve months.

There was no statistically significant difference between the age the Pacelli student became visually-impaired and the knowledge that mosquito caused malaria $(P>0.05)$. Over two-thirds of respondents 200 (76\%) from both schools felt that fever was the most important sign of malaria $(P<$ 0.05). Ninety percent 237 (90.1\%) of respondents from both schools agreed that mosquito nets could protect against malaria $(P<0.05)$. In Pacelli School,

Table 3. Age at which respondents in Pacelli became blind and the correct knowledge that mosquito caused malaria.

\begin{tabular}{|l|c|c|c|}
\hline Age blind in years & $\begin{array}{c}\text { Incorrect Knowledge } \\
n(\%)\end{array}$ & $\begin{array}{c}\text { Correct knowledge } \\
n(\%)\end{array}$ & $\begin{array}{c}\text { Total } \\
>0.05\end{array}$ \\
\hline At Birth & 2 & 29 & 31 \\
\hline $1-5$ & 2 & 35 & 37 \\
\hline More than 5 years & 4 & 28 & 32 \\
\hline Total & 8 & 92 & 100
\end{tabular}

Majority of the mothers of respondents in both schools were clerks, artisans and forewomen $(P>$ 0.05). None of the mothers of the respondents in the public main stream school were doctors, lawyers or engineers. In Pacelli School, one of the mothers was a doctor. The fathers of the respondents in both schools were doctors, lawyers or engineers $33(12.6 \%)$.

In Pacelli School, the greatest number of respondents were from primary one 42 (42\%) while in Oni- only three respondents (3\%) said that drugs could not be a prophylactic against malaria $(P<0.05)$. In Onitolo, 18 (11\%) said that drugs could not be prophylactic against malaria. In Pacelli School, only 15 (15\%) knew that certain ointments could protect against malaria. In Onitolo School, 96 (58.5\%) knew that certain ointments could protect against malaria $(P<0.05)$. In both schools, a total of 147 (55.9\%) had not been absent from school in the past twelve months due to malaria ( $P>0.05)$. 
Table 4. Comparison on major source of information about malaria.

\begin{tabular}{|l|c|c|c|}
\hline $\begin{array}{l}\text { Source (what I know most about } \\
\text { malaria) }\end{array}$ & Pacelli $n(\%)$ & Onitolo $n(\%)$ & $\begin{array}{c}\text { T Value } \\
<0.05\end{array}$ \\
\hline $\begin{array}{l}\text { Doctor/Hospital } \\
\text { Television/Radio }\end{array}$ & $32(32.0)$ & $84(51.2)$ & $116(43.9)$ \\
\hline Mother/Father & $13(13.0)$ & $21(12.8)$ & $34(12.9)$ \\
\hline Teacher/School & $26(26.0)$ & $26(15.9)$ & $52(19.7)$ \\
\hline I don't know & $21(21.0)$ & $6(3.7)$ & $27(10.2)$ \\
\hline Total & $8(8.0)$ & $27(16.5)$ & $35(13.3)$ \\
\hline
\end{tabular}

Table 5. Comparison on the knowledge on cause of malaria.

\begin{tabular}{|l|c|c|c|}
\hline What causes malaria? & Pacelli $n(\%)$ & Onitolo n (\%) & $\begin{array}{c}\text { Total } n(\%) \\
<0.05\end{array}$ \\
\hline Drinking dirty water & $6(6.0)$ & $62(37.8)$ & $68(25.8)$ \\
\hline Mosquito & $92(92.0)$ & $75(45.7)$ & $167(63.3)$ \\
\hline Eating unwashed fruits & $2(2.0)$ & $24(14.6)$ & $26(9.8)$ \\
\hline Eating too much fruits & 0 & $3(1.8)$ & $3(1.1)$
\end{tabular}

On choices of places to go for treatment of mala- treatment. In Onitolo, five of the respondents would ria treatment, none of the respondents from Pacelli prefer to go to the traditional healer for treatment School would decide to go to a traditional healer for of malaria $(P>0.05)$.

Table 6. Comparison on the commonest symptoms of malaria.

\begin{tabular}{|l|c|c|c|}
\hline Commonest sign of malaria & Pacelli $n(\%)$ & Onitolo $n(\%)$ & $\begin{array}{c}\text { Non response } \\
=1, \text { P Value } \\
<0.05\end{array}$ \\
\hline Fever & $87(87.0)$ & $113(69.3)$ & 200 \\
\hline Joint pains and headaches & $2(2.0)$ & $18(11.0)$ & 20 \\
\hline Loss of appetite & $11(11.0)$ & $32(19.6)$ & 43 \\
\hline Total & 100 & 163 & 263
\end{tabular}


Table 7. Responses to questions on preventive measures against malaria.

\begin{tabular}{|c|c|c|c|c|}
\hline \multicolumn{5}{|c|}{ Mosquito net as a protector against malaria } \\
\hline Mosquito net is a protector & Pacelli n (\%) & Onitolo n (\%) & Total & $\begin{array}{c}\text { Non-response } \\
=1 \text {, P Value } \\
<0.05\end{array}$ \\
\hline True & $94(94.0)$ & $143(87.2)$ & 237 & \\
\hline False & $5(5.0)$ & $21(12.8)$ & 26 & \\
\hline Total & 99 & 164 & 263 & \\
\hline \multicolumn{5}{|c|}{ Some drugs as prophylaxis against malaria } \\
\hline Some drugs can be a protector & Pacelli n (\%) & Onitolo n (\%) & Total & P Value $<0.05$ \\
\hline True & $97(97.0)$ & $146(89.0)$ & 243 & \\
\hline False & $3(3.0)$ & $18(11.0)$ & 21 & \\
\hline Total & 100 & 164 & 264 & \\
\hline \multicolumn{5}{|c|}{ Some ointments can be used as a protective barrier } \\
\hline Ointments can protect against malaria & Pacelli n (\%) & Onitolo n (\%) & Total & P Value $<0.05$ \\
\hline True & $15(15.0)$ & $96(58.5)$ & 111 & \\
\hline False & $85(85.0)$ & $68(41.5)$ & 153 & \\
\hline Total & 100 & 164 & 264 & \\
\hline \multicolumn{5}{|c|}{ Sweeping the floor as a protector against malaria } \\
\hline $\begin{array}{l}\text { Sweeping the Floor can protect against } \\
\text { malaria }\end{array}$ & Pacelli n (\%) & Onitolo n (\%) & Total & P Value $>0.05$ \\
\hline True & $33(33.0)$ & $54(32.9)$ & 87 & \\
\hline False & $67(67.0)$ & $110(67.1)$ & 177 & \\
\hline Total & 100 & 164 & 264 & \\
\hline
\end{tabular}


Table 8. Episodes of malaria and treatment of malaria.

\begin{tabular}{|c|c|c|c|c|}
\hline \multicolumn{5}{|c|}{ Comparison on number of times respondents have had malaria in the past 12 months } \\
\hline $\begin{array}{l}\text { Number of malaria episodes in past } 12 \\
\text { months }\end{array}$ & Pacelli n (\%) & Onitolo n (\%) & Total & $\begin{array}{c}\text { Non response } \\
=1, \mathrm{P} \text { Value } \\
>0.05\end{array}$ \\
\hline None & $31(31.3)$ & $74(45.1)$ & 105 & \\
\hline Once & $44(44.4)$ & $49(29.9)$ & 93 & \\
\hline Twice & $15(15.2)$ & $25(15.2)$ & 40 & \\
\hline Thrice & $5(5.1)$ & $11(6.7)$ & 16 & \\
\hline More than 3 times & $4(4.0)$ & $5(3.0)$ & 9 & \\
\hline Total & 99 & 164 & 263 & \\
\hline \multicolumn{5}{|c|}{ Comparison on number of times absent in school in the past 12 months due to malaria } \\
\hline Number of times absent in past 12 months & Pacelli n (\%) & Onitolo n (\%) & Total & $\begin{array}{l}\text { Non Response }=1 \\
\quad P \text { Value }>0.05\end{array}$ \\
\hline None & $63(63.6)$ & $84(51.2)$ & 147 & \\
\hline Once & $23(23.2)$ & $41(25.0)$ & 64 & \\
\hline Twice & $8(8.1)$ & 18(11.0) & 26 & \\
\hline Thrice & $2(2.0)$ & $11(6.7)$ & 13 & \\
\hline More than 3 times & $3(3.0)$ & $10(6.1)$ & 13 & \\
\hline Total & 99 & 164 & 263 & \\
\hline \multicolumn{5}{|c|}{ Comparison on choice of health care provider for treatment of malaria } \\
\hline Choice of health care provider & Pacelli n (\%) & Onitolo n (\%) & Total & $\begin{array}{l}\text { P Value } \\
>0.05\end{array}$ \\
\hline Doctor & $90(90.0)$ & $137(83.5)$ & 227 & \\
\hline Traditional Healer & 0 & $5(3.0)$ & 5 & \\
\hline Chemist & $5(5.0)$ & $11(6.7)$ & 16 & \\
\hline Church/Mosque & $4(4.0)$ & $8(4.9)$ & 12 & \\
\hline I would do nothing & $1(1.0)$ & $3(1.8)$ & 4 & \\
\hline Total & 100 & 164 & 264 & \\
\hline \multicolumn{5}{|c|}{ Comparison of reasons for disliking malaria tablets } \\
\hline Reasons & Pacelli n (\%) & Onitolo n (\%) & Total & $\begin{array}{c}\text { Non response }=2, \\
\mathrm{P} \text { Value }<0.05\end{array}$ \\
\hline It is bitter & $60(60.6)$ & $75(46.0)$ & 135 & \\
\hline Causes hitching & $25(25.3)$ & $34(20.9)$ & 59 & \\
\hline Feels worse & 0 & $26(16.0)$ & 26 & \\
\hline Don't like taking tablets & $14(14.1)$ & $28(17.2)$ & 42 & \\
\hline Total & 99 & 163 & 262 & \\
\hline
\end{tabular}




\begin{tabular}{|c|c|c|c|c|}
\hline \multicolumn{5}{|c|}{ Comparison on number of respondents who do not mind taking injections for malaria treatment } \\
\hline Prefers injections & Pacelli n (\%) & Onitolo $\mathrm{n}(\%)$ & Total & $\begin{array}{l}\text { P Value } \\
<0.05\end{array}$ \\
\hline Yes & $53(53.0)$ & $124(75.6)$ & 177 & \\
\hline No & $47(47.0)$ & $40(24.4)$ & 87 & \\
\hline Total & 100 & 164 & 264 & \\
\hline \multicolumn{5}{|c|}{ Comparison on number of respondents that do not mind taking tablets or capsules for malaria } \\
\hline Prefers tablets/ capsules & Pacelli $n(\%)$ & Onitolo n (\%) & Total & $\begin{array}{l}\text { P Value } \\
<0.05\end{array}$ \\
\hline Yes & $65(65.0)$ & $110(67.1)$ & 175 & \\
\hline No & $35(35.0)$ & 54 (32.9) & 89 & \\
\hline Total & 100 & 164 & 264 & \\
\hline
\end{tabular}

Most of the respondents from both schools 135 (51.5 \%) did not like taking malaria drugs because they tasted bitter. In Onitolo School, 124 (75.6\%) of the respondents did not mind taking injections for the treatment of malaria unlike 53 (53\%) of respondents from Pacelli School that did not mind taking injections for the treatment of malaria $(P<$ 0.05). In Pacelli School, 65 (65\%) of the respondents liked to take tablets/capsules for malaria while $110(67.1 \%)$ of respondents from Onitolo liked to take tablets for the treatment of malaria $(P<$ 0.05). The major source of information on malaria among respondents from Pacelli School and Onitolo School was from the doctor $(P<0.05)$. When the responses from both groups were combined, the least source of information about malaria in both groups was from teacher/school 27 (10.2\%).

\section{Discussion}

The study described the knowledge base of the students from Pacelli School and Onitolo School. They are both primary schools. However, Pacelli School is for the visually-impaired while Onitolo is a main stream public school. The knowledge base of students from both schools was examined on the cause of malaria, the preventive measures against malaria, the treatment of malaria and the source of information on malaria.

The age at which a child became blind was not statistically significant to the knowledge on the cause of malaria ( $P>0.05$ ). In Pacelli School, a greater proportion of the male respondents were blind $(P<0.05)$. This finding was consistent with studies done in Ireland and in Bradford, United Kingdom $[10,11]$. The survey in Ireland was a national survey of children under the age of 16 . The survey conducted in Bradford was done for children between the ages of 5 and 16 years old. In both studies, more males were reported to be blind than females $[10,11]$. However, these findings were contrary to a meta-analytic survey on gender blindness [12]. The meta-analytic study showed that globally, there were more blind females [12]. However, the metaanalytic survey did not include childhood blindness [12]. The surveys in Ireland and Bradford were conducted on children $[10,11]$.

In a study conducted in south eastern, Nigeria, there were more blind male students than females [13]. Another study conducted on the visually impaired students and sighted children in Taiwan also had more visually impaired males. [14]. The researchers explained that parents were reluctant to send blind, female children to boarding schools 
which might also be a possible explanation for the preponderance of males in the visually-impaired group [14].

In comparing the ages of respondents by class in primary school, the students in Pacelli School were older $(P<0.05)$. This could be because Pacelli School is the only school for the visually-impaired in Lagos State where the pupils are taught to read braille. Lagos, Nigeria has a population of 22 million [15] and the schools for the blind are not enough. In south eastern Nigeria, the visually impaired students had an age range of 8-33 years and they were selected from three states [13]. The age range of Pacelli School students was between 6-23 years.

The fathers of respondents from both schools were doctors, engineers or lawyers $(P<0.05)$. The Principal Investigator observed that amongst the children in the main stream school, even if their father worked as a cleaner or an orderly in a hospital, the children insisted that their father was a doctor. This is not surprising because children idolize their fathers [16-18]. Several studies have shown inconsistencies between what the child reports as the parents' occupation and what the parents report as their occupation [16-18]. Studies have also shown that the inconsistencies in children reporting their parents' occupations vary by the gender of the child reporting, the grade level of the child and by the academic achievement of the child [16-18]. Children in lower grades tend to exaggerate the occupations of their fathers while children in the upper grade level at school report their fathers' occupation more accurately [18]. Research also showed that when children were asked to report on their mothers' income and to tell if the mothers received food stamps, the reports by children on their mothers' economic status also varied by the child's gender, age and race [16]. Children also exaggerate their parents' educational level [17]. In Pacelli School, the occupation of the respondents was more consistent because the parents/guardians filled forms prior to enrolling in the school and such information could be verified from the school register.

On the choice of places to go for treatment of malaria, five of the respondents from Onitolo would choose to go to a traditional healer $(P>$ 0.05). None of the respondents from Pacelli School would choose to go to a traditional healer. Pacelli School is a boarding School run by the Catholic Organization and all the respondents in Pacelli School are taught from the Bible which might have influenced their choice not to use a traditional healer. In addition, the answers from the visually-impaired students were coded in by their teachers so that the responses a pupil from the visually-impaired pupil gave were not strictly anonymous to the teachers although the answers were anonymous to the Principal Investigator. Some of the pupils in Onitolo School were brought up in the villages before coming to school in Lagos. In the villages, they have more access to a traditional healer than a doctor. Therefore, students that would prefer to go to a traditional healer could have been influenced by past encounters with traditional healers in the villages. Further, some traditional healers do not know the cause of malaria [19]. A study on the perceived cause of malaria amongst traditional healers in Nigeria showed that some of them felt that malaria was caused by the scorching heat of the sun and they would not refer a suspected case of malaria to a health facility because they believed in the capability of their treatment [19].

The major source of the information the respondents had on malaria was from the doctor/hospital for both groups of respondents $(P<0.05)$. This shows that at some point in the lives of the respondents, they had had health education on malaria through contact with a doctor or from a visit to a hospital. The next major source of information on malaria for both groups was from their mother/ father. In Pacelli School, the teacher/ school was the third most major source of information on ma- 
laria 21 (21\%). In Onitolo School, the teacher/school was the fifth most major source of information on malaria 6 (3.7\%).

A study on the relationship between bible literacy and academic achievements among students attending public schools and students attending Christian schools showed that those that had higher scores on Bible literacy had higher academic achievements [20]. A separate cross-country study also showed that students from private schools obtained higher scores in mathematics, reading and science than those from public schools [21]. Students from Pacelli School outperforming students from Onitolo on knowledge questions on cause of malaria agrees with other studies that find higher academic achievements among private, Christian schools [20, 21].

About thirty percent of the total respondents said malaria was caused by drinking dirty water 68 (25.8\%). Ninety percent of respondents from both schools 237 (90.1\%) knew that mosquito nets could protect against malaria. Forty-two percent of the total respondents knew that certain ointments could protect against malaria 111 (42\%). Thirty-three percent of total respondents said that sweeping the floor could protect against having malaria 87 (33\%). However, a greater proportion of respondents from both groups had the correct knowledge on the cause of malaria. The age at which a child became visually-impaired was not statistically significant to the knowledge on the cause of malaria.

\section{Recommendations}

1. Schools should make concerted efforts to teach their pupils about malaria.

2. There is a need to increase and strengthen the existing human and material resources so that the visually-impaired children can enroll in primary schools at an earlier age.

3. The gaps identified in the knowledge base of the two groups can be articulated in a comprehensive health education program for schools.
4. Teachers from the public main stream school should collaborate with teachers from the Pacelli School because a greater proportion of students from Pacelli School had the correct knowledge on the cause of malaria and the school was their main source of information.

5. The Principal Investigator did not find empirical studies on the knowledge base of malaria or other endemic diseases amongst both groups of students. More studies are needed to identify the knowledge gaps in health topics like malaria.

6. Traditional healers were preferred by some of the students in the treatment of malaria. Traditional healers should be trained in the aetiology of malaria so that any contact they have with students should be an opportunity to also teach them about malaria.

\section{Conclusion}

In Pacelli School, there were more male respondents than female respondents. Fifty-nine of the respondents in Pacelli School were males 59 (59\%). In comparing the age of respondents by class in primary school, the students in Pacelli School were older than the students from the public main stream school $(P<0.05)$. In both groups, Yoruba was the predominant ethnic group 186 (70.5\%) and the $P$ value was $<0.05$. In both groups, Christianity was the predominant religion $(P<0.05)$.

On the knowledge on the cause of malaria, majority of the respondents knew that mosquitoes caused malaria 167 (63.3\%, P<0.05). However, more of the students in Onitolo did not know that malaria was caused by mosquitoes 89 (54.3\%). Both groups of respondents had some misconceptions about the cause of malaria. In Pacelli School, only six students (6\%) did not know that mosquito caused malaria. The age at which a child became blind was not statistically significant to the knowledge on the cause of malaria $(P>0.05)$. The major source of information 
on malaria in both groups was doctor/hospital 116 (43.9\%). Combining both schools, the least source of information on malaria was from teacher/school $(P<0.05) 27$ (10.2\%).

On the choice of health care provider if respondents in both groups had malaria, 227 (86 \%) would prefer to go to a doctor $(P>0.05)$. More than half of the respondents 177 (67\%) did not mind taking injections for treatment of malaria $(P<0.05)$. More than half of the respondents 175 (66.3\%) did not mind taking tablets/capsules for treating malaria ( $\mathrm{P}$ $<0.05)$.

While a lot of research has been conducted on malaria amongst students like measuring the amount of parasites in the blood and direct and indirect cost of malaria, studies have not been conducted on the knowledge base of students on malaria.

Similarly, although numerous researches have been conducted on causes of blindness and the level of intelligence tested on the visually-impaired students [22], there is scant literature on their health information needs and gaps in their health knowledge which can only be identified by knowledge base research such as this. Visually-impaired students should not be assumed to be ignorant on health topics because the results of this study just showed that they outperformed mainstream students on the knowledge question on the cause of malaria.

There are presently few tests if any to determine the health information needs of the visually-impaired. Identifying the gaps in the knowledge base on health topics like malaria would go a long way in developing and planning a need responsive health education program for schools. Misconceptions about diseases should be quickly corrected in the primary schools before the misconception becomes engrained into adulthood by which time, it may be more challenging to correct because such misconceptions may prove harmful as we have seen in the current Ebola virus disease outbreak.

Students in the main stream school indicated preference for malaria treatment by traditional healers.
Traditional healers play a major health role in places where there are not enough health care workers. Therefore, traditional healers should be trained on the cause and treatment of malaria and any misconceptions that they might have should be respectfully debunked.

\section{Competing interests}

The author declares that she has no competing interests.

\section{Authors' contributions}

TTO conceived the study design, assisted in data collection and analysis. TTO wrote the entire manuscript.

\section{Acknowledgements}

The author wishes to express her appreciation to the parents of the pupils, the pupils and the entire staff of Pacelli School and Onitolo School. The author acknowledges Sister J. C. O, the Principal of Pacelli School for the Blind for the oral history of Pacelli School and Mr. J. A. A, the Principal of Onitolo Primary school for the oral history of Onitolo Primary School. The author thanks the management of Lagos University Teaching Hospital, Nigeria my employer at the time of the study.

I would like to acknowledge Virginia Polytechnic Institute and State University's Open Access Subvention Fund (OASF) in my manuscript.

\section{References}

1. WHO 10 facts on malaria; 2014. Cited 28 November 2014; http://www.who.int/features/factfiles/malaria/en/

2. WHO Malaria World Report; 2013. Nigeria Cited 28 November 2014; http://www.who.int/malaria/publications/world_malaria_ report_2013/wmr2013_country_profiles.pdf?ua=1

3. Malaria Overview Context Cited 28 November 2014; http:// www.worldbank.org/en/topic/health/brief/malaria 
4. Onwujekwe O, Uguru N, Etiaba E, Chikezie I, Uzochukwu B, Adjagba A. The Economic Burden of Malaria on Households and the Health System in Enugu State Southeast Nigeria. PloS one. 2013; 8(11): e78362.

5. Orem JN, Kirigia JM, Azairwe R, Kasirye I, Walker O. Impact of malaria morbidity on gross domestic product in Uganda. Int Arch Med. 2012; 5(1): 12-20.

6. Fleming J. Child health and education in Kenyan schools programmes. Health visitor. 1991; 64(3): 80-1.

7. Ng'andu N, Nkowane B, Watts T. The health status of rural primary schoolchildren in Central Zambia. The Journal of tropical medicine and hygiene. 1991; 94(3): 169-74

8. Magnussen P, Ndawi B, Sheshe A, Byskov J, Mbwana K. Malaria diagnosis and treatment administered by teachers in primary schools in Tanzania. Tropical Medicine \& International Health. 2001; 6(4): 273-9.

9. Dike N, Onwujekwe O, Ojukwu J, Ikeme A, Uzochukwu B, Shu E. Influence of education and knowledge on perceptions and practices to control malaria in Southeast Nigeria. Social science \& medicine. 2006; 63(1): 103-6.

10. Goggin M, O'Keefe M. Childhood blindness in the Republic of Ireland: a national survey. British journal of ophthalmology. 1991; 75(7): 425-9

11. Schwarz K, Yeung S, Symons N, Bradbury J. Survey of school children with visual impairment in Bradford. Eye. 2002; 16(5): 530-4.

12. Abou-Gareeb I, Lewallen S, Bassett K, Courtright P. Gender and blindness: a meta-analysis of population-based prevalence surveys. Neuro-Ophthalmology. 2001; 8(1): 39-56.

13. Ezegwui I, Umeh R, Ezepue U. Causes of childhood blindness: results from schools for the blind in south eastern Nigeria. British journal of ophthalmology. 2003; 87(1): 20-3.

14. Chang $\mathrm{C}-\mathrm{H}$, Shih $\mathrm{Y}-\mathrm{H}$. Knowledge of dental health and oral hygiene practices of Taiwanese visually impaired and sighted students. Journal of Visual Impairment \& Blindness (JVIB). 2004; 98(05).

15. Lagos State Government abstract of local government Statistics 2012. Available online: http://www.lagosstate.gov.ng/images/ pageimages/downloadfiles/docs/ABSTRACT_OF_LG\%202012. pdf (accessed on 7 January, 2015).

16. Ridolfo $H$, Maitland A. Factors that influence the accuracy of adolescent proxy reporting of parental characteristics: A research note. Journal of adolescence. 2011; 34(1): 95-103.

17.Kreuter F, Eckman S, Maaz K, Watermann R, Children's Reports of Parents' Education Level: Does it Matter Whom You Ask and What You Ask About? Survey Research Methods; 2010; 4(3); 127-138.

18. Kerckhoff AC, Mason WM, Poss SS. On the accuracy of children's reports of family social status. Sociology of Education. 1973: 219-47.
19. Okeke T, Okafor $H$, Uzochukwu B. Traditional healers in Nigeria: perception of cause, treatment and referral practices for severe malaria. Journal of biosocial science. 2006;38(04):491-500.

20. Jeynes WH. The relationship between Biblical literacy, academic achievement, and school behavior among Christian-and publicschool students. Journal of Research on Christian Education. 2009; 18(1): 36-55.

21. West MR, Woessmann L. 'Every Catholic Child in a Catholic School': Historical Resistance to State Schooling, Contemporary Private Competition and Student Achievement across Countries. The Economic Journal. 2010; 120(546): F229-F255. doi: 10.1111/j.1468-0297.2010.02375.x

22. Atkins S, Cobb R, Keil S, Home S, Wilkins SM. Assessing the ability of blind and partially sighted people: are psychometric tests fair? 2012. Royal National Institute of Blind people (RNIB) Centre for Accessible Information.

\section{Comment on this article:}
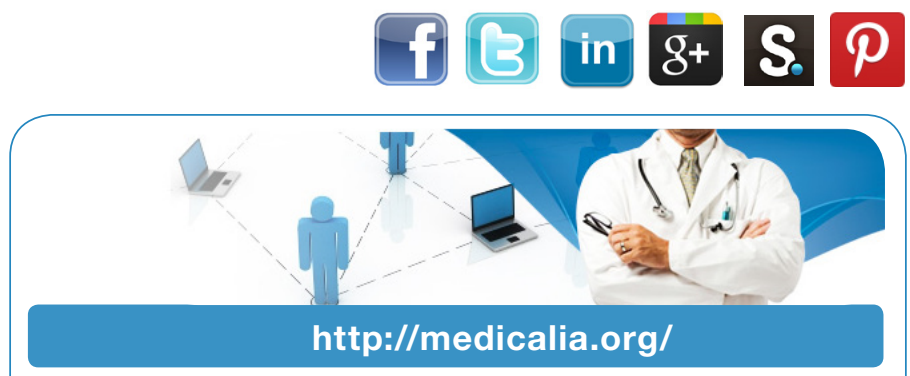

Where Doctors exchange clinical experiences, review their cases and share clinical knowledge. You can also access lots of medical publications for free. Join Now!

\section{Publish with iMedPub \\ http://www.imed.pub}

International Archives of Medicine is an open access journal publishing articles encompassing all aspects of medical science and clinical practice. IAM is considered a megajournal with independent sections on all areas of medicine. IAM is a really international journal with authors and board members from all around the world. The journal is widely indexed and classified Q1 in category Medicine. 